\title{
EVALUASI DAN PERENCANAAN MITIGASI RESIKO PROYEK PEMBANGUNAN JALUR GANDA KERETA API SEMARANG - BOJONEGORO
}

\author{
Aswan Munang ${ }^{1}$, Faisal RM², Agus Mansur ${ }^{3}$ \\ Program Pasca Sarjana Magister Teknik Industri Universitas Islam Indonesia ${ }^{1,2,3)}$ \\ Jl.Kaliurang Km.14,5, Sleman, Yogyakarta \\ Email : aswanmunang88@gmail.com ${ }^{1}$,845210101@staf.uii.ac.id ${ }^{2}$,agusmansur.am@gmail.com ${ }^{3}$
}

\begin{abstract}
Calista Perkasa Mulia ( CPM) ltd is a contracting company of the railway construction. In the project construction of double track railway Semarang-Bojonegoro period April 2012 to December 2013 , scheduling and risk management has not been implemented properly. It could been seen from the works that was not completed on schedule. Therefore, the purpose of this study was to design a project scheduling with precedence diagram method (PDM) and risk management. The results showed that one of the strategies which could be applied to anticipate the delay was the acceleration of the project. With this strategy the project could save as much as Rp730.638.742. Furthermore the risk of sources showed there were $28.21 \%$ of technical risks, $46.15 \%$ of not expected risk and $33.33 \%$ unacceptable risk.
\end{abstract}

Keywords : PDM, Risk Management, Project Management.

\section{PENDAHULUAN}

Semakin meningkatnya perkembangan penduduk semakin meningkat pula kebutuhan yang harus dipenuhi, akibatnya akan terjadi ledakan terhadap permintaan jasa angkutan transportasi yaitu darat, laut dan udara. Dari ketiga jenis tersebut, yang paling banyak digunakan masyarakat adalah transportasi darat dan salah satu moda darat yang dapat dipertimbangkan oleh pengguna disamping angkutan jalan raya adalah kereta api (Pramyastiwi2012). Sampai saat ini angkutan kereta api masih banyak diminati dalam melakukan perjalanan antar kota baik untuk masyarakat pada kota - kota besar maupun kecil. Keunggulan lain kereta api daripada moda transportasi darat yang lain adalah hemat ruang, hemat energi, rendah pencemaran, angka keamanan tinggi, lebih efisien dan juga adaptif dengan perubahan teknologi (Samuel, H \& Nadya, N, 2009). Menurut undang - undang No. 13/1992, perkereta apian adalah salah satu moda transportasi yang memiliki karakteristik dan keunggulan khusus terutama dalam kemampuan mengangkut manusia dan barang.

Data kementerian perhubungan pengguna angkutan kereta api meningkat sangat signifikan pada tahun 2014 sebesar 29,21 persen (Kemenhub 2014). Dengan banyaknya kebutuhan perjalanan membutuhkan infrasturuktur yang besar, salah satu sektor adalah transportasi merupakan sektor yang sangat berperan dalam pembangunan ekonomi yang menyeluruh (Waluya, J \& Nugratama, S 2010).

Dalam proyek pembangunan jalur kereta api ganda Semarang - Bojonegoro periode tahun 2012 - 2013, tampak bahwa pelaksana proyek terlihat belum menerapkan penjadwalan dan menjalankan fungsi manajemen risiko dengan baik bagi perusahaan dan juga dalam pelaksanaan setiap pekerjaan jasa konstruksi. Hal ini dapat dilihat dari beberapa bagian proyek tidak selesai sesuai jadwal perencanaan serta kurangnya pengawasan pekerjaan hal ini merupakan dampak (konsekuensi) bila manajemen resiko tidak mampu di terapkan oleh perusahaan pelaksana jasa konstruksi. Berkaitan dengan masalah proyek ini maka keberhasilan pelaksanaan suatu proyek tepat pada mutu, biaya dan waktunya adalah tujuan yang penting bagi pemilik proyek maupun kontraktor. Pada pembangunan jalur kereta api ganda Semarang - Bojonegoro 
memerlukan adanya penanganan manajemen penjadwalan kerja yang baik, karena itu perlu ditangani dengan perhitungan yang cermat dan teliti. Suatu proyek dikatakan baik jika penyelesaian proyek tersebut efisien ditinjau dari segi waktu, biaya dan mempertinggi efisien kerja baik manusia maupun alat. Untuk mengestimasi waktu dan biaya dalam sebuah proyek maka diperlukan optimalisasi. Menurut Yusrizal, et al., (2013) optimalisasi biasanya dilakukan untuk mengoptimalkan sumber daya yang ada serta meminimalkan kendala namun tetap mendapatkan hasil yang optimal.

Pada kasus pembangunan jalur kereta api ganda Semarang - Bojonegoro, peneliti tertarik pada permasalahan penjadwalan proyek dengan metode PDM dan risk management, sehingga dapat diketahui kegiatan / pekerjaan mana saja yang harus dikerjakan terlebih dahulu atau tidak boleh ditunda pelaksanaannya (kegiatan kritis), agar jadwal proyek teroptimalisasi dengan baik, sehingga keterlambatan dapat dikendalikan dan dihindari (Hervanda dkk2011). Seperti yang diketahui, metode $P D M$ hanya merupakan suatu alat perencanaan dan pengawasan, karena alat ini juga memerlukan suatu cara atau sistem pendukung, sehingga akan didapatkan suatu hasil yang optimal. Pada umumnya, terjadinya kegagalan dalam pelaksanaan suatu proyek menunjukan bahwa pengelolaan proyek belum / tidak sesuai dengan perencanaan dan pengawasan yang matang dan bertanggung jawab.

Dalam proses manajamen risiko, penilaian risiko merupakan salah satu langkah yang sangat baik guna mempermudah perusahaan jasa konstruksi dalam mengindentifikasi setiap faktor-faktor risiko yang bisa saja terjadi dalam pekerjaan konstruksi. tidak hanya sebatas faktor ekonomi (pendanaan) tetapi faktor alam, faktor manusia, faktor politik, dan faktor lingkungan. Faktor - faktor ini merupakan sebagian risiko yang tidak bisa dianggap sepele (mudah) karena semua faktor risiko ini mempunyai dampak yang sangat besar terhadap perusahaan jasa konstruksi dalam menjalankan proyek (Hasibuan dkk 2007). Tidak dapat dipungkiri, bahwa dengan banyaknya aplikasi software pendukung untuk sistem manajemen proyek, mempermudah kontraktor untuk menyelesaikan suatu proyek. Oleh sebab itu, diharapkan dari penelitian ini dapat dipilih alat bantu / software yang lebih baik untuk dipakai sebagai dasar pertimbangan dalam memperbaiki cara - cara lama yang sering menimbulkan kegagalan dalam proyek (Suyatno, 2010; Boser, 2011).

\section{TINJAUAN PUSTAKA}

Manajemen proyek adalah sistem mengelola sembilan bidang pengetahuan yang berkaitan dengan proyek waktu,biaya, ruang lingkup,kualitas, risiko, pengadaan, sumber daya manusia, komunikasi, dan integrasi.Integrasi sembilan bidang pengetahuan dapat membantu manajemen proyek dalam proses pengambilan keputusan yang komplek. pencarian literatur untuk kerangka umum yang digunakan dalam langkah - langkah dari proses pemjadwalan pelaksanan dan manajemen resiko. 
Tabel.1. Daftar Tinjauan Pustaka

\begin{tabular}{|c|c|}
\hline Judul & Metodelogi \\
\hline $\begin{array}{l}\text { Hofmann et al (2015) dengan judul: } \\
\text { Using Precedence Diagram } \\
\text { Method in Process-Oriented } \\
\text { Disaster Response Management } \\
\text { LI Qing et al (2014) dengan judul: } \\
\text { Quality Risk Management Model } \\
\text { for Railwav Construction Projects }\end{array}$ & Metode penelitian menggunakan "A Figure and Four Tables" (AFFTM) \\
\hline $\begin{array}{l}\text { Serpellaa et al (2014) dengan judul: } \\
\text { Risk Management in Construction } \\
\text { Projects: a knowledge - based } \\
\text { approach }\end{array}$ & Metode penelitian menggunakan Risk Management. \\
\hline $\begin{array}{l}\text { Labombang (2014) dengan judul: } \\
\text { Manajemen Risiko dalam Proyek } \\
\text { Konstruksi ditujukan untuk } \\
\text { mengetahui tentang manajemen } \\
\text { resiko pada proyek konstruksi }\end{array}$ & $\begin{array}{l}\text { Metode penelitian menggunakan studi literatur tentang manajemen resiko pada } \\
\text { teori - teori yang relevan. }\end{array}$ \\
\hline $\begin{array}{l}\text { Shiyu } \mathrm{Mu} \text { et al (2014) dengan } \\
\text { judul: Assessing Risk Management } \\
\text { Capability of Contractors in } \\
\text { Subway Projects in Mainland } \\
\text { China }\end{array}$ & Metode penelitian menggunakan deskriptif kuantitatif survei kuesioner \\
\hline $\begin{array}{l}\text { Lestari dkk (2014) dengan judul: } \\
\text { Evaluasi Jadwal dan Perkiraan } \\
\text { Biaya Penyelesaian Proyek Tepat } \\
\text { Waktu dengan Precedence } \\
\text { Diagram Method(PDM) }\end{array}$ & $\begin{array}{l}\text { Metode penelitian menggunakan (Precedence Diagram Method) PDM dan } \\
\text { metode Cost and Schedule Trade Off. }\end{array}$ \\
\hline $\begin{array}{l}\text { Novianti dkk (2011) dengan judul: } \\
\text { Pemodelan Resiko Pendapatan } \\
\text { Proyek Infrastruktur Jalan Tol }\end{array}$ & Metode penelitian menggunakan Delphi dan fault tree analysis. \\
\hline $\begin{array}{l}\text { Norken et al (2012) dengan judul: } \\
\text { Manajemen Risiko pada Proyek } \\
\text { Konstruksi di Pemkab Jembrana } \\
\text { ditujukan untuk mengidentifikasi } \\
\text { risiko pada proyek konstruksi } \\
\text { secara komprehensif }\end{array}$ & $\begin{array}{l}\text { Metode penelitian menggunakan deskriptif kualitatif, brainstroming, } \\
\text { wawancara dan dengan menggunakan kuisioner }\end{array}$ \\
\hline $\begin{array}{l}\text { Abdulhasan (2009) dengan judul: } \\
\text { Integrating Assembly Planning and } \\
\text { Line Balancing Using Precedence } \\
\text { Diagram }\end{array}$ & $\begin{array}{l}\text { Metode penelitian (Computer Method of Sequencing Operations for Assembly } \\
\text { Lines of Assembly Planning and Line Balancing) }\end{array}$ \\
\hline $\begin{array}{l}\text { Orcale Primavera (2009) dengan } \\
\text { judul: Using Relationship } \\
\text { Diagrams to Enhance the Critical } \\
\text { Path Method of Project Scheduling }\end{array}$ & $\begin{array}{l}\text { Metode Diagram Hubungan (RDM) varian dari CPM dalam Oracle's } \\
\text { Primavera Risk Analysis }\end{array}$ \\
\hline
\end{tabular}

\section{METODE PENELITIAN}

\subsection{Ruang Lingkup Penelitian}

Penelitian ini merupakan penelitian studi pada proyek pembangunan jalurganda kereta api Semarang-Bojonegoro. Lokasi penelitian di PT. Calista Perkasa Mulia pada bulan April 2012 sampai dengan Desember 2013.

\subsection{Metode}

Metodologi yang digunakan dalam penelitian menggunakan metode $P D M$ (Precedence Diagram Method) danRisk Management.Metode PDM dilakukan dengan bantuan program Microsoft Project 2007. Penjadwalan dilakukan dari awal proyek dimulai dari data perencanaan, pelaksanaan hingga proyek selesai yang terkait untuk analisis mampu dikerjakan Microsoft Project. Selain itu juga akan memperoleh besarnya prakiraan total biaya dan waktu untuk penyelesaian proyek.

Risk Management adalah proses sistematis untuk mengidentifikasi, menganalisis dan menanggapi resiko proyek. Manajemen resiko sebagai proses identifikasi, pengukuran, dan kontrol keuangan dari sebuah resiko yang mengancam aset dan penghasilan dari 
sebuah perusahaan atau proyek yang dapat menimbulkan kerusakan atau kerugian pada perusahaan tersebut.

\section{HASIL DAN PEMBAHASAN}

\subsection{Deskripsi Umum Proyek}

Proyek pembangunan jalur kereta api ganda Semarang - Bojonegoro adalah proyek yang membentang dari propinsi jawa tengah sampai ke jawa timur. Proyek yang ditinjau dalam penelitian ini adalah proyek pembangunan jalur ganda KA Km.45+991 s/d Km.48+858 sepanjang 2.867 meter jalan rel yang lokasi proyek berada di antara Demak dan Purwodadi. Nilai Kontrak : Rp.45.413.282.618, Waktu Pelaksanaan Perencanaan : 570 Hari Kalender Tanggal

Tabel.2.Daftar Pekerjaan, Durasi,Predecessors dan Successors

\begin{tabular}{|c|c|c|c|c|c|}
\hline & Durasi & Predecessors & Successors & $\begin{array}{l}\text { Slack } \\
\text { (Hari) }\end{array}$ & Critica \\
\hline \multicolumn{6}{|l|}{$\begin{array}{l}\text { Pekerjaan Tubuh Baan dan } \\
\text { Track }\end{array}$} \\
\hline Sondir tanah & 28 & $4 \mathrm{SS}$ & 17 & 42 & No \\
\hline $\begin{array}{l}\text { Perbaikan tanah dasar dengan lapisan } \\
\text { geotextile }\end{array}$ & 301 & $19 ; 17 ; 18$ & $30 \mathrm{SS} ; 32$ & 42 & No \\
\hline $\begin{array}{l}\text { Timbunan Tanah tubuh jalan KA dengan } \\
\text { borrow material }\end{array}$ & 287 & $29 S S ; 20 ; 23 ; 22$ & 32 & 0 & Yes \\
\hline $\begin{array}{l}\text { Menggali tanah untuk tubuh jalan KA dan } \\
\text { membuang }\end{array}$ & 189 & 18 & $45 ; 55 ; 48 \mathrm{SS} ; 49 \mathrm{SS} ; 41 ; 57 ; 58$ & 56 & No \\
\hline Pengadaan dan menggelar sub balas & 56 & $30 ; 48 ; 49 ; 29 ; 41$ & $35 ; 36 ; 37 ; 34 S S$ & 0 & Yes \\
\hline Pengadaan dan memasukan balas dengan KA & 56 & $35 ; 36 ; 37 ; 38 ; 39 F S-35$ & 14 & 0 & Yes \\
\hline $\begin{array}{l}\text { Pengadaan dan memasukan balas dengan } \\
\text { truck }\end{array}$ & 84 & $32 \mathrm{SS}$ & $38 ; 39 ; 40$ & 0 & Yes \\
\hline $\begin{array}{l}\text { Bantalan Kayu utk MJ lengkap dgn } \\
\text { accecories }\end{array}$ & 56 & 32 & 33 & 0 & Yes \\
\hline Pemasangan bantalan beton dan accessories & 28 & 32 & $38 ; 39 ; 40 ; 33$ & 0 & Yes \\
\hline Menyetel dan pemasangan rel R.54 & 56 & 32 & 33 & 0 & Yes \\
\hline Mengelas rel dengan las thermit & 28 & $34 ; 36$ & 33 & 0 & Yes \\
\hline $\begin{array}{l}\text { Mengerjakan angkat listring HTT, MTT, } \\
\text { PBR dan VDM }\end{array}$ & 63 & $34 ; 36$ & 33FS-35 & 0 & Yes \\
\hline
\end{tabular}

\subsection{Penentuan Lintasan Kritis}

Dari tabel diatas dapat diketahui bahwa lintasan kritis dengandari proyek
Rencana Pekerjaan dimulai : 30 Maret 2012, Tanggal Rencana Pekerjaan selesai : 20 Oktober 2013.

\subsection{Penjadwalan PDM (Precedence Diagram Method)}

Dari data pelaksanaan proyek ternyata mengalami keterlambatan sehingga durasi keseluruhan menjadi 605 hari kalender dari perencanaan awal 570 hari kalender. Oleh karena itu perlu dilakukan optimlasisasi dalam penjadwalan pelaksanaan proyek ini. Penjadwalan proyek pada saat pelaksanan proyek dilakukan dengan metode PDM diolah dengan menggunakan Software Microsoft Project 2007. 
Tabel.3. Daftar Pekerjaan Lintasan Kritis

\begin{tabular}{|c|c|c|c|c|c|}
\hline Pekerjaan & Durasi & Start & Finish & $\begin{array}{l}\text { Free } \\
\text { Slack }\end{array}$ & Critical \\
\hline Start proyek & & Fri $30 / 03 / 12$ & Fri 30/03/12 & & \\
\hline \multicolumn{6}{|l|}{ Pekerjaan Tubuh Baan dan Track } \\
\hline $\begin{array}{l}\text { Timbunan Tanah tubuh jalan KA dengan borrow } \\
\text { material }\end{array}$ & 287 & Mon 20/08/12 & Sun $02 / 06 / 13$ & 0 & Yes \\
\hline Pengadaan dan menggelar sub balas & 56 & Mon $03 / 06 / 13$ & Sun $28 / 07 / 13$ & 0 & Yes \\
\hline Pengadaan dan memasukan balas dengan KA & 56 & Mon 23/09/13 & Sun $17 / 11 / 13$ & 0 & Yes \\
\hline Pengadaan dan memasukan balas dengan truck & 84 & Mon 03/06/13 & Sun $25 / 08 / 13$ & 0 & Yes \\
\hline Bantalan Kayu utk MJ lengkap dgn accecories & 56 & Mon 29/07/13 & Sun $22 / 09 / 13$ & 0 & Yes \\
\hline pemasangan bantalan beton dan accessories & 28 & Mon 29/07/13 & Sun $25 / 08 / 13$ & 0 & Yes \\
\hline Menyetel dan pemasangan rel R.54 & 56 & Mon $29 / 07 / 13$ & Sun $22 / 09 / 13$ & 0 & Yes \\
\hline Mengelas rel dengan las thermit & 28 & Mon 26/08/13 & Sun $22 / 09 / 13$ & 0 & Yes \\
\hline $\begin{array}{l}\text { Mengerjakan angkat listring HTT, MTT, PBR } \\
\text { dan VDM }\end{array}$ & 63 & Mon 26/08/13 & Sun $27 / 10 / 13$ & 0 & Yes \\
\hline
\end{tabular}

(Sumber: Data Primer Diolah)

\subsection{Percepatan Pekerjaan dengan Crashing Program}

Pada prinsipnya percepatan dilakukan untuk meningkatkan produktivitas, sehingga durasi pekerjaan kritis dapat dipercepat sehingga dapat menghindari ketelambatan penyelesaian proyek. Proses crashing dilakukan berdasarkan kebutuhan sumber daya pada pada tiap - tiap pekerjaan agar durasinya dapat dipercepat. Tetapi dapat juga berdasarkan lama durasi dan besarnya volume perkerjaan.

Hasil dari adanya percepatan proyek Crashing, pelaksanaan proyek mengalamai ketelambatan menjadi 602 hari dengan penambahan biaya sebesar Rp150.092.429 kemudian dengan dilakukan crashing, maka dapat sesuai dengan durasi rencana semula yaitu 570 hari. Hal ini berarti telah terjadi penurunan durasi dari pelaksanaan sebesar 35 hari. Namun penurunan durasi proyek ini diiringi dengan peningkatan biaya proyek sebesar Rp708,733,721 sebagai akibat dari penambahan peralatan, tenaga kerja dan jam kerja. Kontrak kerja yang berlaku untuk proyek pembangunan jalur ganda kereta untuk ketelambatan dikenakan denda sebesar (1/1000) x (nilai kontrak) perhari. Sehingga dendan perhari adalah Rp45.413.283, untuk keterlambatan selama 35 hari adalah Rp1,589,464,892 ditambah dengan keterlambatan pelaksanan Rp150.092.429. Maka dengan dilakukan crashing mendapatkan penghematan biaya Rp730.638.742.

\subsection{Analisis Manajemen Resiko Proyek}

Identifikasi risiko yang terjadi pada pelaksanaan proyek pembangunan jalur ganda KA Km.45+991 s/d Km.48+858 dan pengamatan langsung dilapangan. Identifikasi risiko juga dilakukan dengan melakukan brainstorming dan interview dengan pihak yang memiliki kompetensi memberikan masukan terhadap risiko yang terjadi pada pelaksanaan pembangunan jalur ganda KA. Identifikasi resiko menurut Godfrey (1996) adalah bersumber dari aktivitas. Jenis sumber resiko berdasarkan aktivitas antara lain politis, perencanaan, proyek, teknis, lingkungan, keselamatan, alami, ekonomi, kriminal, manusia dan keuangan. Untuk dapat melakukan identifikasi resiko, terlebih dahulu dilakukan identifikasi terhadap sumber risiko. Resiko yang diperoleh dari hasil identifikasi langsung di lapangan dapat dikelompokkan berdasarkan tabel berikut : 
Tabel .4.Identifikasi Resiko Berdasarkan Aktivitas dan Sumber Risiko Pada Tahap Pelaksanaan.

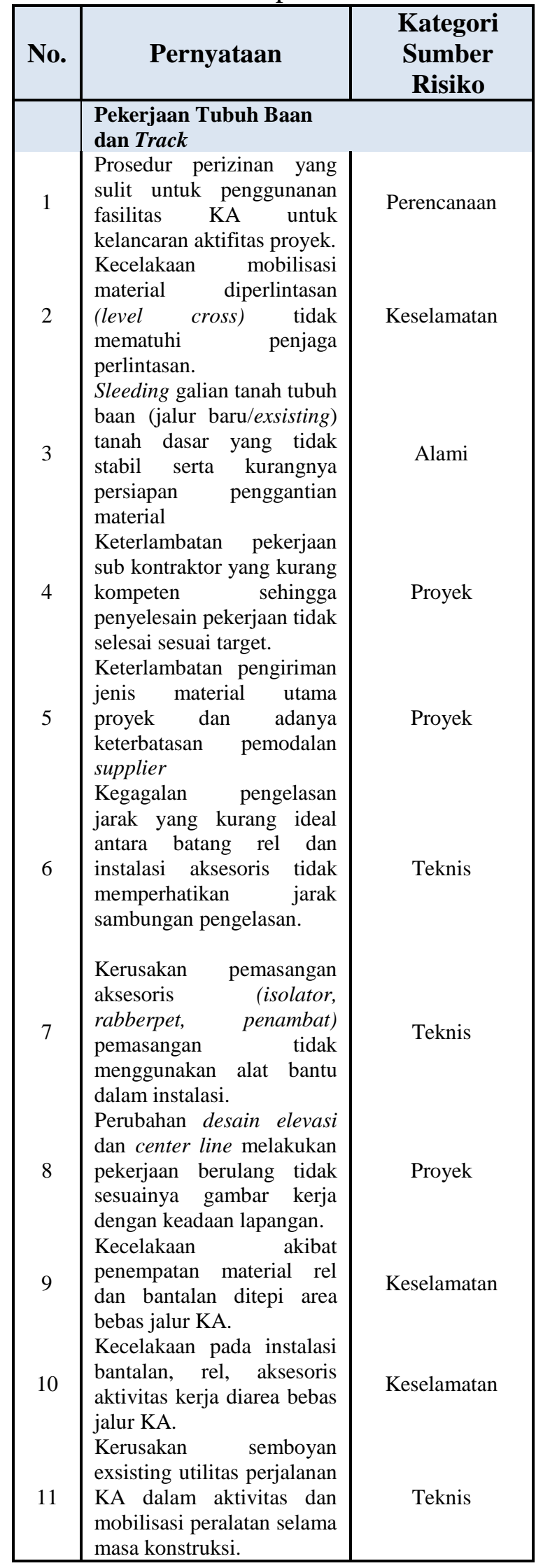

Tabel .4.1.Identifikasi Resiko

Berdasarkan Aktivitas dan Sumber Risiko Pada Tahap Pelaksanaan.

\begin{tabular}{|c|l|c|}
\hline No. & \multicolumn{1}{|c|}{ Pernyataan } & $\begin{array}{c}\text { Kategori } \\
\text { Sumber } \\
\text { Risiko }\end{array}$ \\
\hline 12 & $\begin{array}{l}\text { Kecelakaan kendaraan } \\
\text { umum diperlintasan } \\
\text { sebidang diarea proyek } \\
\text { tidak mematuhi penjagaan } \\
\text { perlintasan tanpa palang. }\end{array}$ & Keselamatan \\
$\begin{array}{l}\text { Kerusakan lingkungan } \\
\text { proyek, saluran perairan, } \\
\text { tanaman, debu dan } \\
\text { genangan air } \\
\text { dipermukiman warga yang } \\
\text { bersingungan dengan } \\
\text { pembangunan jalur ganda. }\end{array}$ & Lingkungan \\
\hline
\end{tabular}

(Sumber: Data Primer Diolah)

Resiko yang teridentifikasi pada pelaksanaan pembangunan jalur ganda KA Km.45+991 s/d Km.48+858 sebanyak 39 (tiga puluh sembilan resiko). Menurut kategori sumber resiko - resiko terbanyak adalah resiko teknis, yaitu sebanyak 11 (sebelas) resiko atau $28,21 \%$ dari keseluruhan resiko yang teridentifikasi. Persentase jumlah resiko dapat dijelaskan pada tabel 5 .

Tabel.5.Persentase Jumlah Resiko

Berdasarkan Sumber Resiko

\begin{tabular}{|c|c|c|c|}
\hline No. & Sumber risiko & Jumlah & $\%$ \\
\hline 1 & Politis (political) & 1 & 2,56 \\
\hline 2 & Lingkungan & 1 & \\
\hline 3 & $\begin{array}{l}\text { (environment) } \\
\text { Perencanaan } \\
\text { (planning) }\end{array}$ & 1 & $\begin{array}{r}2,56 \\
2,56\end{array}$ \\
\hline 4 & $\begin{array}{l}\text { Pemasaran } \\
\text { (market) }\end{array}$ & 0 & 0,00 \\
\hline 5 & $\begin{array}{l}\text { Ekonomi } \\
\text { (economic) }\end{array}$ & 1 & 2,56 \\
\hline 6 & $\begin{array}{l}\text { Keuangan } \\
\text { (financial) }\end{array}$ & 0 & 0,00 \\
\hline 7 & Alami (natural) & 3 & 7,69 \\
\hline 8 & Proyek (project) & 7 & 17,95 \\
\hline 9 & Teknis (technical) & 11 & 28,21 \\
\hline 10 & Manusia (human) & 3 & 7,69 \\
\hline 11 & $\begin{array}{l}\text { Kriminal } \\
\text { (criminal) }\end{array}$ & 3 & 7,69 \\
\hline 12 & $\begin{array}{l}\text { Keselamatan } \\
\text { (safety) }\end{array}$ & 8 & 20,51 \\
\hline & Jumlah & 39 & 100,00 \\
\hline
\end{tabular}

(Sumber: Data Primer Diolah) 


\subsection{Penilaian Resiko (Assessment Risk)}

Penilaian resiko pada dasarnya adalah melakukan perhitungan atau penilaian terhadap dampak resiko yang telah teridentifikasi, besar kecilnya dampak risiko akan dapat dikategorikan, mana merupakan resiko dengan tingkat yang utama (major risks), yang mempunyai dampak besar dan luas yang membutuhkan pengelolaan, atau tidak (minor risks), yang tidak memerlukan penanganan khusus karena tingkat risiko ada dalam batas - batas yang dapat diterima. Godfrey, (1996) menguraikan besarnya dampak risiko merupakan perkalian dari frekuensi (likeli hood) dengan konsekuensi (consequence) dari risiko yang telah teridentifikasi. Frekuensi (likelihood) adalah besarnya peluang terjadinya kerugian yang potensial menyebabkan kegagalan investasi. Penilaian resiko dilakukan dengan mengalikan kemungkinan (likelihood) dan pengaruh (consequences) seperti yang terlihat pada lampiran. Berdasarkan hasil perkalian tersebut diperoleh nilai risiko untuk dapat menentukan tingkat penerimaan risiko (acceptability of risk). Hasil penerimaan resiko dapat dijelaskan sebagai berikut :

Tabel.6. Hasil Penerimaan Risiko (Acceptability of Risk)

\begin{tabular}{|c|c|c|}
\hline Acceptability & $\mathbf{f}$ & $\%$ \\
\hline $\begin{array}{l}\text { 1. Unacceptable } \\
\text { (tidak dapat diterima) }\end{array}$ & 13 & 33,33 \\
\hline $\begin{array}{l}\text { 2. Undesirable } \\
\text { (tidak diharapkan) }\end{array}$ & 18 & 46,15 \\
\hline 3. Acceptable (dapat diterima) & 7 & 17,95 \\
\hline 4. Negligible (dapat diabaikan) & 1 & 2,56 \\
\hline Jumlah & 39 & 100,00 \\
\hline
\end{tabular}

\subsection{Respon Risiko (Risk Respon Planning)}

Keberadaan resiko - resiko dominan (major risk) akan memberikan pengaruh yang sangat besar pada proyek pembangunan jalur ganda KA Km.45+991 s/d Km.48+858. resiko - resiko yang termasuk dalam kategori risiko yang tidak dapat diterima (unacceptable) dan risiko yang masuk dalam kategori tidak diharapkan (undesirable) memerlukan adanya tindakan mitigasi untuk mengurangi dampak yang ditimbulkan. Mitigasi risiko dapat dilakukan dengan mengurangi risiko (risk reduction), menahan risiko (risk retention), mengalihkan risiko (risk transfer) dan menghindari risiko (risk avoidance). Tindakan - tindakan mitigasi yang dilakukan dalam penelitian ini didapatkan dari hasil analisis, wawancara dengan pihak yang berkompeten yang memiliki tanggung jawab terhadap terjadinya resiko untuk dapat dilakukan tindakan mitigasi agar dapat mengurangi dampak negatif yang ditimbulkan.Tindakan mitigasi resiko sebagai berikut :

Tabel.7. Mitigasi Resiko

\begin{tabular}{|c|c|}
\hline Sumber Resiko & Mitigasi \\
\hline & \\
\hline asi material & an melekat \\
\hline $\begin{array}{ll}\text { diperlintasan } & \text { (level } \\
\text { cross) } & \text { tidak }\end{array}$ & $\begin{array}{l}\text { saat mobilisasi material } \\
\text { dan malakukan }\end{array}$ \\
\hline mematuhi penjaga & koordinasi perjalanan \\
\hline rlin & $\begin{array}{l}\text { kereta api dengan pihak } \\
\text { stasiun terdekat. }\end{array}$ \\
\hline Kura & Mengadakan pelatihan \\
\hline $\begin{array}{l}\text { pengawasan alat berat } \\
\text { saat beraktivitas yang }\end{array}$ & $\begin{array}{l}\text { singkat kepada operator } \\
\text { tentang keselamatan }\end{array}$ \\
\hline banyak & kerja dan me \\
\hline $\begin{array}{l}\text { bersinggungan } \\
\text { dengan jalur bebas }\end{array}$ & $\begin{array}{l}\text { trainwatcheruntuk } \\
\text { melakukan pengawasan }\end{array}$ \\
\hline $\begin{array}{l}\text { KA atau tidak dalam } \\
\text { pengawasan } \\
\text { trainwatcher }\end{array}$ & $\begin{array}{l}\text { setiap aktifitas alat } \\
\text { berat. }\end{array}$ \\
\hline Kece & th \\
\hline $\begin{array}{lr}\text { instalasi } & \text { bantalan, rel } \\
\text { dan } & \text { aksesoris }\end{array}$ & $\begin{array}{l}\text { koordinasi antar stasiun } \\
\text { terdekat untuk jadwal }\end{array}$ \\
\hline & pejalaan \\
\hline & mempersiapkan tenaga \\
\hline & $\begin{array}{l}\text { ngalaman dalam } \\
\text { lasi. }\end{array}$ \\
\hline $\begin{array}{l}\text { Sleeding galian tanah } \\
\text { tubuh baan (jalur } \\
\text { baru/exsisting) tanah } \\
\text { dasaryang tidak stabil }\end{array}$ & $\begin{array}{l}\text { Melakukan pekerjaan } \\
\text { disaat perjalanan KA } \\
\text { tidak padat dan tidak } \\
\text { meninggalkan galian }\end{array}$ \\
\hline $\begin{array}{l}\text { serta kurangnya } \\
\text { persiapan } \\
\text { penggantian material. }\end{array}$ & $\begin{array}{ll}\text { terbuka disekitaran } \\
\text { tubuh baan }\end{array}$ \\
\hline
\end{tabular}

(Sumber: Data Primer Diolah) 


\subsection{Aspek Hubungan PDM (Precedence Diagram Method) dan Risk Management}

Pengelolaan proyek berskala besar yang berhasil, memerlukan perencanaan, penjadwalan, dan pengkoordinasian yang hati-hati dari berbagai aktivitas yang saling berkaitan. Untuk itu diperlukan prosedur yang didasarkan atas penggunaan network (jaringan) dan teknik - teknik network dalam perencanaan, penjadwalan, dan pengkoordinasian suatu proyek. Hasil evaluasi dari pelaksanaan proyek pembangunan jalur ganda kereta api Semarang - Bojonegoro dengan metode PDM menggunakan Microsoft Project 2007 menunjukkan adanya keterlambaan pelaksanaan. Keterlambatan terjadi dilintasan kritis pada item tahapan pekerjaan Tubuh Baan dan Track sehingga sebagian besar item pekerjaan mengalami keterlambatan maka percepatan dengan (crashing) perlu dilakukan untuk mengantisipasi denda yang timbul akibat keterlabatan penyelesaian proyek.

Menurut kategori tahapan pekerjaan, risiko-risiko terbanyak adalah pada Pekerjaan Tubuh Baan dan Track, yaitu sebanyak 13 (tigabelas) item resiko atau $33.33 \%$ dari keseluruhan resiko yang teridentifikasi. Kemudian diikuti dengan resiko terbanyak kedua pada tahap Pekerjaan Sipil / Pendukung Track, yaitu 7 (tujuh) item risiko atau $17.95 \%$. Pekerjaan Tubuh Baan dan Track memiliki tingkat risiko yang cukup tinggi dapat dilihat dari hasil analisis pada frekuensi risiko, konsekuensi risiko serta penilaian risiko memiliki keterkaitan dengan pelaksanaan proyek jalur ganda kereta api Km.45+991 s/d Km.48+858. Pengelolaan mananajemen risiko dapat membatu dalam menghindari atau mengurangi risiko yang memunculkan ketidakpastian dan kerugian baik secara proyek, teknis maupun bisnis. Maka respon resiko perlu dilakukan, salah satunya mitigasi resiko untuk mengurangi dampak yang ditimbulkan. Mitigasi secara umum yang dapat dilakukan adalah menambah tenaga pengawasan dan keamanan khususnya berkaitan dengan pelaksanaan K3 dalam proyek jalur ganda kereta api.

Dari data pelaksanaan proyek keterlambatan teridentifikasi dari item dalam tahapan Pekerjaan Tubuh Baan dan Track serta Pekerjaan Sipil / Pendukung Track sehingga proyek mengalami keterlabatan penyelesaian. Penjadwalan menggunakan Microsoft Project 2007 dapat membantu memantau perkembangan pelaksanaan sehingga dapat memeberikan informasi lebih akurat tentang perkembangan proyek masih sesuai dengan perencanaan atau mengalami keterlambatan pelaksanaan maka dapat mengambil strategi alternatif lebih cepat dalam menangani permasalahan proyek kemudian manajemen risiko dapat memebantu dalam mengantisipasi kemungkinan - kemungkinan yang akan mengancam keberlangsungan proyek sehingga perlu dilakukan identifikasi risiko, analisis risiko, respon resiko serta melakukan doumentasi secara detail tentang pengelolaan resiko dari hasil pengalaman yang ada ataupun sumber resiko baru maka selanjutnya dapat menjadikan organisasi proyek handal dalam pengelolaan manajemen proyek.

\section{KESIMPULAN}

Berdasarkan penelitian dan analisis yang telah dilakukan, maka dapat disimpulkan :

1. Hasil evaluasi kinerja peroyek menunjukkan adanya keterlambatan proyek mengalamai selama 35 hari sehingga perlu dilakukan percepatan pekerjaan proyek. Bila dilakukan percepatan proyek (crashing), pelaksanaan proyek dapat sesuai dengan durasi rencana semula yaitu 570 hari maka percepatan pekerjaan proyek merupakan salah satu strategi yang dilakukan dapat menghemat biaya sebesar Rp730.638.742.

2. Berdasarkan analisis data resiko yang teridentifikasi pada pelaksanaan Pembangunan jalur ganda KA Baru Km.45+991 s/d Km.48+858, terdapat sebanyak 39 (tiga puluh sembilan risiko). 
Menurut kategori sumber resiko terbanyak adalah resiko teknis, yaitu sebanyak 11 (sebelas) resiko atau $28,21 \%$ dari keseluruhan resiko serta dalam penilaian resiko terbanyak adalah (undesirable) tidak diharapkan sebanyak 18 risiko (46,15\%), dan diikuti oleh risiko yang tidak dapat diterima (unacceptable) sebanyak 13 risiko $(33,33 \%)$. Resiko - resiko yang teridentifikasi memerlukan adanya tindakan mitigasi untuk mengurangi dampak yang ditimbulkan.

\section{DAFTAR PUSTAKA}

Abdulhasan, Bushra Basheer. Integrating Assembly Planning and Line Balancing Using Prcedence Diagram. Eng. \& Tech. Journal, Vol.27, No.5, 2009.

Boser, Richard. Part 3 Scheduling Fundamentals: Activity

Definition and Sequencing. Time Management, 2011.

Gil, Nuno, Bruce S. Tetherb. Project risk management and design flexibility: Analysing a case and conditions of complementarity. Research Policy 40 (2011) 415428.www.elsevier.com/locate/res pol. 2014.

Godfrey, P.S., Sir William Halcrow and Partners Ltd. Control of Risk A Guide to Systematic Management Of Risk from Construction. Wesminster London : Construction Industry Research and Information Association (CIRIA), 1996.
Hasibuan, Kisman, Arifal Hidayat dan Pada lumba. Analisis Manajemen terhadap Faktor Keterlambatan Proyek Konstruksi di Lingkungan Dinas Pariwisata Kabupaten Rokan Hulu. Program Studi Teknik Sipil. Fakultas Teknik Universitas Pasir Pengaraian, 2007.

Halim, Winda dan Rainisa Maini Heryanto. Analisis Tren Kecelakaan pada Sektor Transportasi di Indonesia (Moda Transportasi: Kereta Api). Jurusan Teknik Industri, Universitas Kristen Maranatha, Bandung, 2013.

Hervanda, Yosi, Ariefal Hidayat dan Anton Ariyanto. Analisis Keterlambatan Proyek Konstruksi Jalan yang DisebabkanFaktor Material di Kabupaten Rokan Hulu. Program Studi Teknik Sipil. Fakultas Teknik Universitas Pasir Pengaraian, 2011.

Kementrian perhubungan Laporan Produksi Penumpang dan Barang Angkutan Kereta Api di Jawa dan Sumatera 2014. Dilihat 6 Februari 2015. Diakses www.kemenhub/uu/25673/bps/rep ort2014.go.id, 2014

LI Qing, LIU Rengkui, ZHANG Jun, SUN Quanxin. 2014. Quality risk management model for railway construction projects. International Symposium on Safety Science and Technology. Procedia Engineering 84 195203. www.sciencedirect.com, 2014.

Labombang, M. Manajemen Risiko dalam Proyek Konstruksi. Fakultas Teknik Universitas Tadulako Palu, 2014. 
Lestari, Cindy, Agus Ristono, Trismi Ristyowati. Evaluasi Jadwal dan Perkiraan Biaya Penyelesaian Proyek Tepat Waktu dengan Precedence Diagram Method (PDM). Studi Kasus PT. Arkindo Bandung. Program Studi Teknik Industri. Fakultas Teknologi Industri. UPN "Veteran" Yogyakarta.

Norken, I.N., Astana, I.N.Y., dan Manuasri, L.K.A. Manajemen Risiko pada Proyek Konstruksi di Pemkab Jembrana. Fakultas Teknik Sipil Universitas Udayana Denpasar, 2012.

Nikmah, Siti Khoirun dan Valentina Sri Wijiyati. Proyek Efisiensi Perkeretaapian. Working Paper No.1, 2008. NGO in Special Consultative Status with the Economic and Social Council of the United Nations, 2008.

Oracle Primavera. Precedence Diagram Method, 2011.

Pramyastiwi, Deasy Elfarischa, Imam Hardjanto, Abdullah Said. Perkembangan Kualitas pelayanan perkereta apian sebagai Angkutan Publik dalam rangka mewujudkan Transportasi Berkelanjutan (Studipada PT. KAI Daops 8 Surabaya). Jurnal Administrasi Publik (JAP), Vol.1. No.3. h.61-69, 2012.

Undang - Undang No. 13 Tahun 1992 tentang Perkeretaapian.
Samuel, H \& Nadya, N, Service quality, perceive value, satisfaction, trust, dan Loyalty pada PT. Kereta Api Indonesia menurut penilaian Pelanggan surabaya. Jurnal Manajemen Pemasaran. Vol. 4, NO. 1, april 2009: h 23-37, 2009.

Serpellaa, Alfredo Federico, Ximena Ferradaa, Rodolfo Howarda, Larissa Rubioa. 2014. Risk management in construction projects: a knowledge-based approach. 27th IPMA World Congress. Procedia - Social and Behavioral Sciences 119 653662. www.sciencedirect.com, 2014.

Shiyu $\mathrm{Mu}, \mathrm{Hu}$ Cheng, Mohamed Chohr Wei Peng. 2014. Assessing risk management capability of contractors in subway projects in mainland China. International Journal of Project Management 32 452-460. www.sciencedirect.com, 2014.

Suyatno. Analisis Faktor Penyebab Keterlambatan Penyelesaian Proyek Gedung (Aplikasi Model Regresi). Program PascaSarjana. UNDIP Semarang, 2010.

Waluya, J dan Nugratama, S. Lingkungan Dan Transportasi. REGION Volume II. No. 2 September 2010.

Yusrizal, Sofyan M Saleh, NoerFadhly. Studi Revitalisasi Jalur Kereta Api Banda Aceh - Batas Sumatera Utara. Jurnal Teknik Sipil ISSN 2302-0253 Pascasarjana Universitas Syiah Kuala 13 Pages pp. 26 - 38 Volume 2, No. 1, Februari 2013 - 26, 2013. 